\title{
THE ALBERT VALDMAN AWARD
}

We are pleased to announce that the recipients of the Albert Valdman Award for outstanding publication in 2016 are Akira Murakami and Theodora Alexopoulou for their September 2016 article, "L1 Influence on the Acquisition Order of English Grammatical Morphemes: A Learner Corpus Study." Please join us in congratulating these authors on their contribution to the journal and to the field. 